\title{
MINIATURE RADIOGRAPHY
}

\footnotetext{
1. MBBS, MCPS, FCPS

Associate Professor of Radiology,

Consultant Radiologist

Rawal Institute of Health Sciences, Islamabad.

2. MBBS, MPH.

Associate Professor / Head of Community Medicine Department Rawal Institute of Health Sciences, Islamabad.

\section{Correspondence Address:}

Dr. Saif-Ud-Din Saif

Associate Professor of

Community Medicine

Rawal Institute of Health Sciences,

Khanna Dak, Lehtrar Road, Islamabad

saifdin75@yahoo.com
}

Article received on:

13/12/2013

Accepted for Publication:

20/01/2014

Received after proof reading

28/05/2014

\section{INTRODUCTION}

Mass Miniature Radiography is done to examine chests of large number of patients. It permits rapid survey of large group of workers and members of the armed forces at the time of recruitment'. MMR unit is transportable. It can be operated in a van or on premises where large number of workers are employed. Unless a mobile generator is available the electrical main supply is very important item. Use of fast film and adequate processing minimizes the need for re- examination.

MMR is an intermediate form of radiological examination providing permanent record of many individuals in comparatively short time. MMR cannot replace X-ray chest in completeness and precision. This study was designed to find out the workload share of radiology department made by MMR The result of the study will help the policy makers in developing regulatory and practice guidelines for judicial use of MMR to make it cost effective

\section{PATIENTS AND METHODS}

A total number of 1401 MMR were done at the department of radiology POF Hospital Wah Cantt. These included patients of both sexes. The study was started on 01st August 2009 and ended on $31^{\text {st }}$ July 2011.

Patients of all ages were included. X-Ray power unit with Odelca $70 \mathrm{SLI}$ Camera accommodating 50 exposure roll film magazine was used. This camera does not require film edge perforation. Unit was operated on the hospital premises. Green sensitive 70 into $30.5 \mathrm{~mm}$ size non-perforated fluorography film roll was used. Manual developing was done in all the cases. Identification was achieved by serial number of patient on right side of film. Large film was taken when MMR was technically unsatisfactory or to confirm a pathological condition All MMR during study were evaluated and proper record of radiological findings was maintained. Age, gender and clinical information provided on the request form were noted. 


\section{RESULTS}

A total number of 1401 patients were examined during the period of two years. There were two main categories of study subjects. The majority (988) reported for pre employment medical check up. The second group came for routine annual medical checkup. (Table I). There was striking male preponderance (M: F 12:1). (Table II). Ages of patients ranged from 16 years to 60 years. The largest part (64\%) of the patients belonged to age group 20 to 30 years. (Table III). 96 individuals (07\%) were recalled for large film. Technically inadequate MMR was the reason for recall in most of $(05 \%)$ the cases. (Table V). Pathology was confirmed by full size radiograph in $(02 \%)$ of the patients. The most common abnormalities were pulmonary tuberculosis (16) and cardiomegaly (09). (Table IV).

\begin{tabular}{|c|c|}
\hline Annual medical check up & 413 \\
\hline Pre-employment check up & 988 \\
\hline Total & 1401 \\
\hline \multicolumn{2}{|c|}{ Table-I. Symptoms of the study subjects } \\
\hline \multicolumn{2}{|c|}{ Male } \\
\hline Female & 1291 \\
\hline Total & 110 \\
\hline & Table-II. Gender \\
\hline
\end{tabular}

\begin{tabular}{|l|c|}
\hline Less than 20 years & 170 \\
\hline 20 to 30 years & 900 \\
\hline 30 to 40 years & 81 \\
\hline More than 40 years & 250 \\
\hline \multicolumn{2}{|c|}{ Table-III. Age of subjects } \\
\hline \multicolumn{2}{|c|}{} \\
\hline
\end{tabular}

Out of 1401 patients attended 988 were advised MMR for pre employment medical checkup and 413 reported for annual checkup (Table I ). 91\% (1291) were male and 110 were female (Table II). Majority (64\%) of the subjects belonged to age group 20 to 30 years. (Table III).16 patient had pulmonary tuberculosis. (Table IV)

\begin{tabular}{|l|c|}
\hline Pulmonary tuberculosis & 16 \\
\hline Cardiomegaly & 09 \\
\hline Normal & 1376 \\
\hline Total & 1401 \\
\hline \multicolumn{2}{|c|}{ Table-IV. Radiological findings } \\
\hline
\end{tabular}

\begin{tabular}{|l|r|}
\hline Technically inadequate MMR & 71 \\
\hline To confirm pathology & 25 \\
\hline Total & 96 \\
\hline \multicolumn{2}{|c|}{ Table-V. Indications for large films } \\
\hline
\end{tabular}

\section{DISCUSSION}

MMR or Abreugraphy is a technique for mass screening of tuberculosis using a miniature photograph of the screen of an x-ray fluoroscopy of the thorax. MMR was invented in 1935 by, Dr. Manuel Dias de Abreu, a Brazilian pulmonologist. It has received several different names according to the country where it was adopted e.g. mass radiography in UK and miniature chest radiograph in USA. In many countries MMR was quickly adopted in the 1950s. In Brazil and in Japan, tuberculosis prevention laws went into effect, obligating $60 \%$ of the population to undergo MMR screening.

23000 persons were examined by MMR in Greater London to find out incidence of tuberculosis in civilians during wartime in 1943. A number of 1500 individuals were examined per week by an eight members team ${ }^{2}$. Mass radiography surveyed 7 per cent of general population per year in England in 1960s.Eighty percent cases of tuberculosis were detected by other methods. Contacts of tuberculosis should not be radio graphed by MMR. Full size film should be used for this purpose.470,000 persons had MMR in Liverpool in 4 weeks in $1959^{3}$.

System of tuberculosis finding by MMR was established in Japan in 1951. Number of individuals examined per year was 54 millions .In 1996 MMR detected 228 cases of tuberculosis out of 965,440 subjects .MMR is not cost effective in 
areas having less than 50 cases per 100,000 tuberculosis. Japan Anti-Tuberculosis Association (JATA) reported the detection of 228 cases in 965,440 chest radiographs in 1996 alone $^{4}$.

MMR is being practiced in recruiting and training centers of armed forces of Pakistan. Tuberculosis can be detected in recruits who have been passed as fit by clinical examination. Advantage of MMR is less acreage of X-ray films used and on that account some fund saving may be accomplished. If it is not possible to screen entire population by MMR, then it should at least be employed selectively in:

a. Contacts of tuberculosis patients

b. Occupants of mental institutions

c. General risk group, like doctors, nurses, and workers of coal industries ${ }^{5}$.

In Karachi SZABIT is carrying out Mass Miniature Radiography (MMR) with the collaboration of Pakistan Anti-Tuberculosis Association (PATA) and the MMR Committee of Pakistan. A specialized XRay Machine is fitted in a Van with a generator and laboratory facilities for developing X-Ray film rolls. The Van is taken to various children schools in the underprivileged areas of Karachi. A medical Doctor and a Technician conduct the medical tests on site. Over 22,000 X-Rays, which include over 6000 school children, have been taken at the following locations for early detection of lung pathologies. 15 Schools, 13 Factories, 7 Pharmaceutical Companies, 4 Hospitals, 3 Banks, 3 Afghan Refugees Camps and 2 Security Services. The research results are regularly reported to the $\mathrm{WHO}$.

In POF hospital Wah Cantt Codelca camera was installed in 1985. Jeep mounted Codelca camera was procured in 1986 and stopped functioning in 2000.Number of roll used from Jan 1985 to date is 350 meaning 87500 individuals screened in 22 years or4000 subjects per year. Image quality of standard size film is far better. 35 by $35 \mathrm{~cm} \mathrm{X} \mathrm{ray}$ film provides 60 time larger image as compared with 70 by $30 \mathrm{~mm}$ size MMR film. An advantage from record keeping view is less space required by MMR. Roll film record is easily accessible for reference, many thousands of chest images occupying a very small space. The space needed to store 3000 MMR images is equal to space needed by 100 large films.

Sri Lanka is using miniature radiography as a screening procedure in chest clinics. In Sri Lanka graphite miners are regularly submitted to radiography at static MMR units located near mines .MMR detects both pulmonary tuberculosis and pneumoconiosis ${ }^{6}$. MMR in Indian Army showed high incidence of pulmonary tuberculosis in artillary, infantry and medical corps. MMR is an efficient tool of tuberculosis case finding in high incidence groups ${ }^{7}$.

MMR is most useful at detecting tuberculosis infection in the asymptomatic phase and it should be combined with tuberculin skin tests The sharp increase in tuberculosis in all countries with large exposure to HIV is probably mandating a return of MMR as a screening tool focusing on high-risk populations, such as intravenous drug users.

As its name implies mass miniature radiography is undertaken for a large number of subjects. Examinations are made at rate of 500 or more per day ${ }^{1}$. Patient may be recalled for full size film confirmation. Films should be handled carefully because all the spots are enlarged by magnifying lens used for viewing MMR. Camera taking nonperforated films has advantage of larger image as compared to films having perforated edges. Larger image makes diagnosis easy.

MMR films are viewed by projection screen or using direct magnification.

Homogeneous light of proper brightness and color with dim room lights improve pickup rate . $^{8}$ During interpretation of film there is chance of over-reading and under-reading ${ }^{9}$. MMR film reading session should be limited in time to avoid making mistakes due to mental fatigue. Homogeneous light of proper brightness and colour with dim room lights improve pickup rate ${ }^{6}$.

MMR machine serves as dual purpose unit using 
miniature or standard films as required. Large chest film can be taken by MMR units so if MMR PROGRAMME is discontinued due to some reason the same equipment can be used for conventional radiography. $45 \mathrm{~mm}$ wide films are too small for accurate reading. $100 \mathrm{~mm}$ wide films are too expensive. $45 \mathrm{~mm}$ wide films strike a reasonable balance between accuracy and economy.

MMR has slightly higher dose of radiation than standard chest radiograph. So it should be avoided in children and pregnant woman MMR imparts gonadal dose 1.0 mrad which causes negligible danger of genetic hazard. This dose is slightly more as compared with full size chest film ${ }^{10}$.

In the course of routine MMR many abnormal cardiovascular shadows are also encountered. Enlargement of cardiac shadow can be easily detected on miniature film. Slight scoliosis and slight rotation of the patient cause apparent cardiac enlargement ${ }^{11}$.

As a mass screening program for low-risk populations, the procedure was largely discontinued in the 1970s, following recommendation of the $\mathrm{WHO}$ due to three main reasons:

1. The dramatic decrease in the incidence of tuberculosis in developed countries.

2. Decreased benefits/cost ratio in low risk groups $^{12}$.

3. Risk of ionizing radiation doses.

Currently, 13 of the 26 European countries use MMR as the primary screening tool to detect TB in prisoners, immigration applicants and foreign workers. Italy, Switzerland, Norway, Netherlands, Japan and the United Kingdom have permanent MMR programs for this purpose. Elderly populations are also a good target for MMR because they have a higher risk of tuberculosis (85 per 100,000 in developed countries).

\section{CONCLUSIONS}

The film used for MMR is suggestive rather than diagnostic .It merely separates persons for whom further investigations are required. The international standard is taking 500 or more exposures per day by one MMR unit'. According to this criterion our facility is much underutilized. it is better to discontinue MMR if the number of patients falls much short of accepted standards because of decreased benefit/cost ratio.

Copyright (C) 20 Jan, 2014.

\section{REFERENCES}

1. K.C. Clark. Positioning in Radiography. $8^{\text {th }}$ ed. London Ilford Limited; 1964. 686-694.

2. Herman E Hilleboe Am J Public Health Nations Health 1945 July,35(7): 759-760

3. Hugh Paul. The Control of Diseases 2nded. Living stone London 1964. 240-242.

4. Ohmori M, Wada M, Uchimura K, Nishii K, Shirai Y, Aoki M. Discussing the current situation of tuberculosis case-finding by mass miniature radiography in Japan. Kekkaku. 2002 Apr;77(4):329-39. In Japanese. Kekku, Pub Med 2002 April ,77(4) 329-339.

5. M.B . Zafar, Introducing Radio diagnosis and Imaging, 1985.42.

6. D.J..Weatherall .Oxford Textbook of Medicine $3^{\text {rd }}$ ed. Oxford University Press Oxford 1996.662.

7. Major M.C.Sanyal.The incidence of pulmonary tuberculosis in Indian army. Indian $\mathrm{J}$.Tub.,vol IV, No6.Sept 1957.139-150.

8. Stephen Chapman and Richard Nakiely. A guide to radiological procedures. 3rd ed. London. Bailliere Tindall; 1993. 402.

9 Proceed Natl TB \& Chest Dis Work Conf $18^{\text {th }}$, Banglore India 16-19 Jan 1962, 64-85.

10 Conway Don. Canad. M.A.J 1961 vol 84.573-575.

11. Alex Maclean and Alfred Rogen. Mass Miniature Radiography in the detection of heart disease, $\mathrm{Br}$ Heart J.1949 July;11(3):264-270.

12. Schwartzman K, Menzies D. Tuberculosis screening of immigrants to low-prevalence countries. A cost-effectiveness analysis. Am J Respir Crit Care Med. 2000 Mar;161 (3 Pt 1):780-9. 